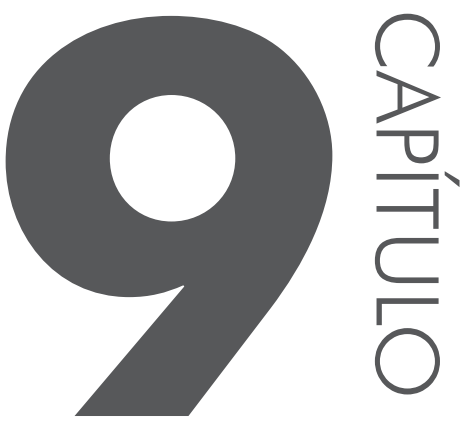

\title{
QUALIDADE DA ALIMENTAC̣ÃO DO IDOSO: UMA ANÁLISE DA INGESTÃO ALIMENTAR DOS FREQUENTADORES DO RESTAURANTE POPULAR DE LONDRINA
}

Isabela Fernanda Bacili Martins Juliany Piazzon Gomes Marcos Jerônimo Goroski Rambalducci

\section{INTRODUC̣ÃO}

Nos últimos anos, o Brasil tem demonstrado queda no crescimento populacional e aumento na expectativa de vida dos brasileiros, o que, por conseguinte, 
caracteriza mudanças na estrutura etária, que, alinhada à urbanização e às condições de subdesenvolvimento econômico, resultam em alterações no padrão de consumo alimentar (ABREU et al., 2001).

Mudanças nos padrões alimentares estão relacionadas à forma em que é realizada a produção e distribuição alimentícia em conjunto com a crescente urbanização, o que terá como consequência mudanças na saúde da população. Segundo Almeida et al. (2010), a alimentação dos idosos requer atenção especial, pois, com o passar do tempo, as funções normais são alteradas, gerando necessidades de modificação qualitativa e quantitativa nos hábitos alimentares.

Os problemas de saúde predominantes entre os idosos, tais como diabetes e hipertensão, estão, em sua maioria, relacionados à alimentação inadequada e à falta de políticas de prevenções eficientes. As medidas preventivas podem reduzir o número de óbitos e proporcionar melhores condições na qualidade de vida dos idosos.

Com o aumento da população idosa e as transições nos padrões alimentares, são disponibilizadas novas oportunidades de segmentos alimentares a serem introduzidas no mercado. Dentro dessas oportunidades, destaca-se esse nicho de mercado, ou seja, alimentação desse grupo populacional específico, que atualmente é pouco explorada e possui grande potencial de consumo.

Levando em consideração o que foi descrito, uma pergunta pode ser colocada: O que está no prato, como principal refeição, dos londrinenses com mais de 60 anos?

Responder a essa questão poderá significar lançar as bases para uma mudança de comportamento alimentar e mercadológico, permitindo adequar políticas públicas elucidativas quanto a padrões de alimentação saudáveis.

A população brasileira com mais de 60 anos de idade saltou de 14.536 mil em 2000 para 20.591 mil em 2010 , passando de $8,5 \%$ para $10,8 \%$ da população brasileira em apenas uma década, e as estimativas apontam para uma representação ainda maior para os próximos vinte anos, quando deverá atingir $20 \%$ do total da população (IBGE, 2010).

Em uma população em que a pirâmide etária torna-se cada vez mais constituída por pessoas idosas, é fundamental promover a prática de uma alimentação saudável, mas a condição primeira para programas dessa natureza é ter conhecimento aprofundado e confiável a respeito do comportamento alimentar das pessoas em tal faixa etária. Dessa forma, esta pesquisa visou avaliar a ingestão alimentar de idosos frequentadores do Restaurante Popular da cidade de Londrina.

\section{AUMENTO DA EXPECTATIVA DE VIDA}

No Brasil e em vários países em desenvolvimento, a expansão da população idosa está ocorrendo ligeiramente, sem a correspondente modificação nas condi- 
ções de vida. O envelhecimento vem acontecendo de modo simultâneo ao aparecimento de doenças como diabetes, hipertensão e obesidade, entre outras, que surgem devido à influência de diversos fatores, mas, principalmente, provenientes do mau hábito de alimentação (TINÔCO et al. 2007).

Com a mudança demográfica ocorrida nos últimos anos, quando se pensa em indivíduos idosos, a principal preocupação está relacionada a quem cuidará dessa crescente população e como serão vividos os anos adquiridos com o aumento da expectativa de vida (CAMARGOS; PERPÉTUO; MACHADO, 2005). A população idosa no Brasil exibe um aspecto de crescimento progressivo e ágil, fazendo com que a longevidade componha uma questão atual, carecendo de uma sociedade que obtenha meios para possibilitar benefícios à população idosa (PAZ; SANTOS; EIDT, 2006).

Segundo Mendes (2005), nos países em desenvolvimento a população idosa tem aumentado significativamente, porém, as condições para estabelecer qualidade de vida aos idosos não acompanham o crescimento demográfico. Desse modo, a preocupação com a mudança do perfil populacional tem como consequência a realização de estudos objetivando subsidiar políticas e programas adequados que beneficiem essa parcela da população.

Pesquisas de Projeção de População divulgadas pelo Instituto Brasileiro de Geografia e Estatística (IBGE) apontam que, em 1970, a população idosa brasileira era composta por 4,7 milhões de pessoas idosas. Houve crescente aumento em 2007, passando para 17,9 milhões de pessoas. Ao realizar uma estimativa quanto ao número da população de idosos no mundo e a tendência dos gêneros, deduz-se que haverá cerca de 259,8 milhões de idosos em 2050, sendo 53\% dessa população feminina, contra $47 \%$ masculina (IBGE, 2007).

Atualmente, o processo de envelhecimento populacional no mundo está em ritmo acelerado, especialmente no Brasil, considerando que, de acordo com o Censo Demográfico realizado em 2010 pelo IBGE, somam-se 20,5 milhões de pessoas consideradas idosas no país, o equivalente a $11 \%$ da população (IBGE, 2010).

\subsection{Novo perfil nutricional e suas consequências}

O processo de industrialização, urbanização e o aumento da renda permitiram maior acesso aos alimentos, ocasionando uma transição nutricional que, como consequência, expõe a população ao risco de doenças crônicas (SCHMIDT, 2011). A alimentação no processo de envelhecimento tem importância certificada em estudos epidemiológicos e clínicos que demonstram a relação entre a dieta e o surgimento de doenças crônicas não transmissíveis (DCNT) (CERVATO et al., 2005).

Conforme Acuña e Cruz (2004), a condição nutricional manifesta as necessidades fisiológicas por nutrientes para conservar as funções adequadas do organismo, 
de modo que gere equilíbrio entre a ingestão e os nutrientes necessários. A transição nutricional, processo que envolve mudanças nos padrões alimentares, ocasionou mudanças na epidemiologia populacional, resultando em um novo perfil de morbimortalidade, sendo caracterizado por sobrepeso, obesidade, problemas cardiovasculares e diabetes, principais causas de óbitos brasileiros (MALTA et al., 2006).

Alimentação saudável é aquela composta por vários alimentos de origem vegetal e animal, que portam todos os grupos de nutrientes, objetivando sempre o equilíbrio e a harmonia, unindo alimentos de qualidade e quantidades adequadas aos indivíduos. As recomendações alimentares realizadas para a população idosa devem considerar as alterações fisiológicas, destacando o risco para o desenvolvimento das doenças crônicas não transmissíveis (FREITAS; PHILIPPI; RIBEIRO, 2011).

De acordo com Macedo, Schmourlo e Viana (2012), a alimentação saudável tem atuado como fator de prevenção e também de possível cura de algumas doenças da modernidade. Devido à sociedade apresentar inúmeras patologias relacionadas à alimentação, observa-se a necessidade de dispor de uma alimentação que previna tais transtornos.

Os hábitos alimentares dos idosos possuem grande influência daqueles que fazem parte da sua convivência diária, os familiares. Os membros de uma família podem constituir referência influente nos padrões adotados para o consumo alimentar (CASOTTI et al., 2002). Problemas como incapacidades físicas e falta de coordenação motora podem afetar os hábitos alimentares dos idosos, pois alimentos que geram qualquer dificuldade de manipulação durante suas refeições podem desestimular o consumo, prejudicando o equilíbrio nutricional dessa população (LIMA-FILHO; QUEVEDO-SILVA; FOSCACHES, 2012).

Desse modo é importante que os idosos se alimentem com prazer, pois essa sensação está associada ao aproveitamento da diversidade de alimentos, respeitando a acessibilidade e a cultura regional, a busca de novas adaptações disponíveis adequadas às peculiaridades de cada pessoa idosa, preservando as características sensoriais que motivam o consumo de uma refeição (BRASIL, 2009).

\section{2 $O$ envelhecimento e suas necessidades}

O envelhecimento faz parte do ciclo natural de vida, com isso, torna-se necessário estabelecer rotinas de vida saudáveis. A adoção de uma alimentação saudável contribui para a promoção da saúde, prevenção de doenças, segurança alimentar e nutricional, proporcionando qualidade de vida e um ritmo favorável de envelhecimento (BRASIL, 2009).

Apesar de o envelhecimento fazer parte da natureza humana, este submete o organismo a diversas mudanças anatômicas e funcionais, afetando as condições 
de saúde e o estado nutricional, do qual se destacam o declínio da taxa metabólica basal, em virtude do baixo gasto energético, aumento do tecido adiposo e redução do percentual de massa muscular, devido à diminuição da atividade física, alimentação inadequada e baixa quantidade da água corporal (CATÃO; XAVIER; PINTO, 2011).

Com o avanço natural da idade, as funções normais como a mastigação e a deglutição são alteradas, dificultando o momento do consumo do alimento. Tornam-se necessárias modificações qualitativas e quantitativas nos hábitos alimentares, de modo que as refeições sejam planejadas e utilizadas de maneira a contribuir com a segurança e satisfação da pessoa idosa (BRASIL, 2009).

Nas últimas décadas, a população brasileira vem mostrando influentes transições em seus hábitos alimentares e estilo de vida. Diante das mudanças e da falta de informações sobre a disposição alimentar dos idosos, esses conhecimentos compõe um material essencial para a elaboração de estratégias que prosperem o quadro de saúde dos idosos (TINÔCO et al. 2007).

O crescimento da população idosa revela um vasto mercado de consumo alimentar, necessitando de adequações nos alimentos de maneira que possibilitem um maior tempo de vida saudável para os consumidores idosos (ALMEIDA et al., 2010). Para Acevedo (1998), no Brasil, a partir de 1990, o mercado maduro passou a ter como foco os consumidores idosos, pois é uma lacuna de mercado que, se explorado adequadamente, tem grande potencial lucrativo, pois faz parte de um conceito de mercado diferenciado e com características peculiares.

Almeida et al. (2010) salientam que a alimentação adequada aos idosos deve ser equilibrada, contendo proteínas, vitaminas e sais minerais; ter baixo teor de gordura; ser rica em fibras; ser moderada em sal e açúcar; ser de fácil digestão; ter aspectos agradáveis e ingestão de líquidos, sendo as refeições efetuadas em menor quantidade, porém com maior número de vezes ao dia, de modo que sejam respeitados os hábitos adquiridos ao longo da vida (apud RODRIGUEZ; DIOGO, 2000¹).

Segundo Philippi et al. (1999), a pirâmide alimentar representada pela Figura 9.1, é dividida em quatro níveis e oito grupos compostos com alimentos semelhantes, sendo definido, para cada grupo, o número de porções diárias a serem consumidas. O primeiro nível pertence ao grupo 1, cereais, tubérculos e raízes; segundo nível, ao grupo 2, hortaliças, e ao grupo 3, frutas; o terceiro nível pertence ao grupo 4, leite e produtos lácteos, ao grupo 5, carnes e ovos e ao grupo 6, leguminosas; o quarto nível ao grupo 7, óleos e gorduras, e ao grupo 8, açúcares e doces.

1 RODRIGUES, R. A. P.; DIOGO, M. J. D.E (Orgs.). Como cuidar dos idosos. 3.ed. Rio de Janeiro: Papirus, 2000. Coleção Viva Idade. 


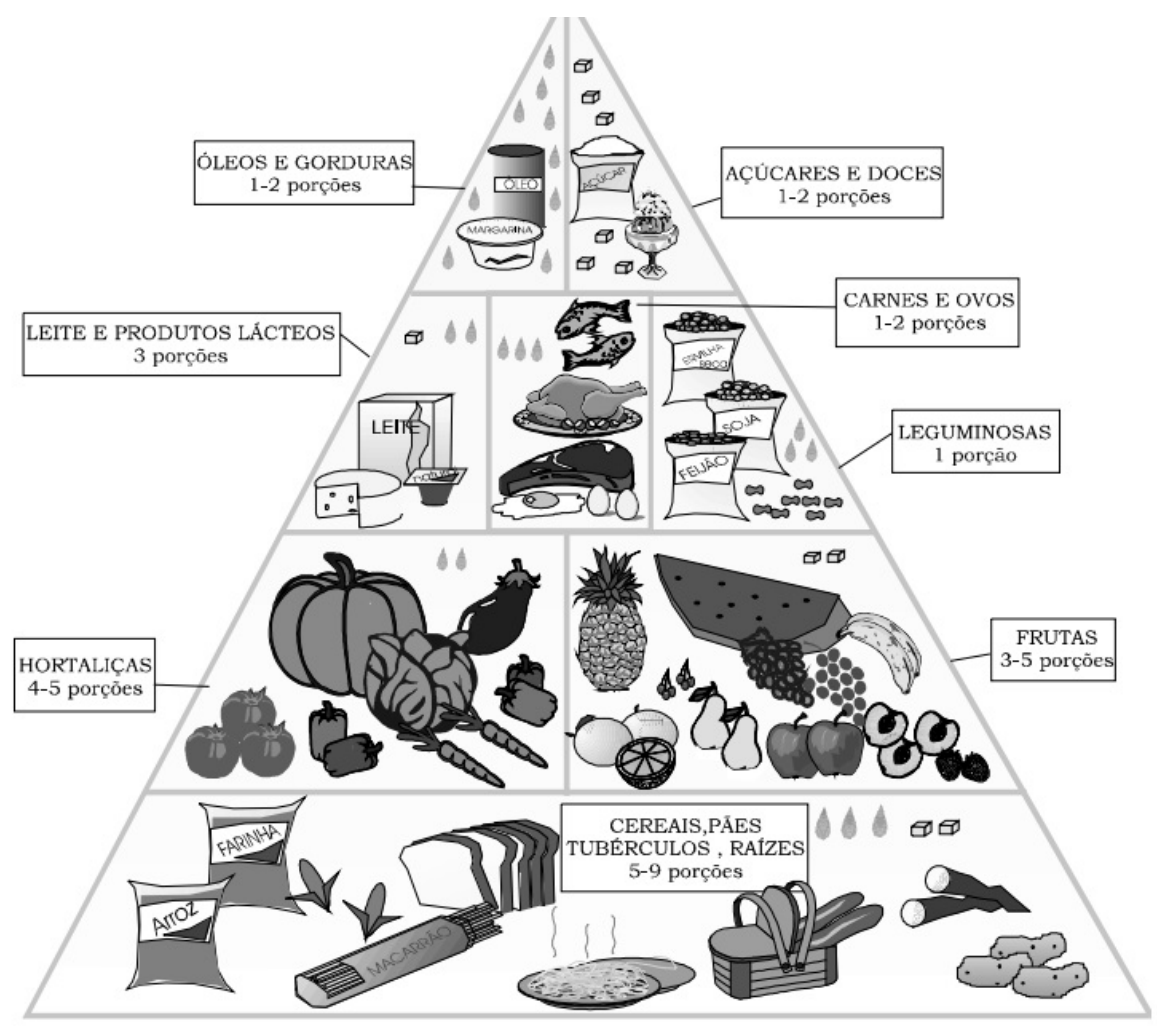

Fonte: Adaptada de PHILIPPI et al. (1996).

Figura 9.1 Pirâmide alimentar

O Quadro 9.1 destaca os alimentos que compõem cada grupo e a respectiva quantidade em porções de um consumo ideal.

Quadro 9.1 Composição de alimentos por grupo e respectivo consumo ideal

\begin{tabular}{ccc}
\hline GRUPO & COMPOSIÇÃO & CONSUMO IDEAL \\
\hline Grupo 1 & Cereais, pães, tubérculos e raízes. & 5 a 9 porções \\
Grupo 2 & Hortaliças & 4 a 5 porções \\
Grupo 3 & Frutas & 3 a 5 porções \\
Grupo 4 & Leite e produtos lácteos & 3 porções \\
Grupo 5 & Carnes e ovos & 1 a 2 porções \\
Grupo 6 & Leguminosas & 1 porção \\
Grupo 7 & Óleos e gorduras & 1 a 2 porções \\
Grupo 8 & Açucares e doces & 1 a 2 porções \\
\hline
\end{tabular}

Fonte: Adaptado de PHILIPPI et al. (1996). 
Para Tinôco et al. (2007), a alimentação, sob a perspectiva nutricional, dispõe os constituintes dos alimentos (carboidratos, proteínas, lipídeos, vitaminas, minerais e fibras) como essenciais à saúde e à qualidade de vida dos indivíduos. $\mathrm{O}$ consumo de vitaminas e minerais, em quantidades adequadas, é influente para a ocorrência de várias reações químicas do organismo.

\subsection{Faixa etária do idoso}

Para que seja utilizada uma definição amplamente aceita de quem é idoso, mesmo havendo dificuldades para tal, torna-se vantajoso utilizar o critério etário. O envelhecimento é compreendido de diversas maneiras diferentes, ponderando sempre as variações culturais, fazendo parte dos processos biológicos, aparência física, eventos de desengajamento da vida social, como aposentadoria, e o aparecimento de novos papéis sociais, como o de avós (ALMEIDA et al., 2010).

Nos países desenvolvidos, são considerados idosos aqueles que possuem mais que 65 anos de idade. Já no Brasil, caso dos países em desenvolvimento, é considerado idoso o cidadão que possuir idade igual ou acima de 60 anos. Em âmbito local, a prefeitura de Londrina, cidade situada no estado do Paraná, considera idosos aqueles com 60 anos de idade ou mais, estando de acordo com a Política Nacional do Idoso, o Estatuto do Idoso e as demais leis correlacionadas (LONDRINA, 2010).

Em Londrina, segundo os aspectos demográficos da população idosa, em 2009 havia 61.822 habitantes considerados idosos, representando $12,1 \%$ do total estimado em 510.710 habitantes do município (LONDRINA, 2009).

\subsection{Idoso: consumidor em potencial}

Atualmente, os idosos apresentam mudanças em seus costumes, estilos de vida, atitudes de compras, desejos e expectativas. Em sua maioria, esse grupo detém razoável poder aquisitivo, decisão de compra, tempo, preocupação com a qualidade de vida, saúde e bem-estar, podendo ser considerado consumidor com grande potencial, pelo fato de a faixa etária pertencente a pessoas com mais de 60 anos estar em crescimento demográfico (SIEVERT; TAÍSE, 2007).

O crescimento da população idosa representa um grande mercado de consumo alimentar, pois o consumo de alimentos adequados permite um maior tempo de vida saudável para esses consumidores em potencial e, consequentemente, gera redução de custos para o estado e a sociedade, levando em consideração que uma melhoria na condição de vida, através de uma alimentação saudável e equilibrada, pode ocasionar uma queda nos custos gerados para o governo e a sociedade quanto a prevenções de doenças e manutenção da saúde de seus idosos (ALMEIDA et al., 2010). 
O mercado tem que se alterar de acordo com as modificações ocorridas com o perfil dos consumidores. Desse modo, é imprescindível a criação de novos produtos para que se preencham as necessidades e expectativas geradas por esse público específico. Porém, os idosos são um público-alvo pouco explorado mercadologicamente, tornando primordial a empresa ter maior empenho em conhecer e estudar essa nova demanda (SIEVERT; TAÍSE, 2007).

Lima-Filho (2008) considera que há poucos estudos sobre o comportamento alimentar do idoso, sugerindo uma melhor compreensão do tema, fator que está relacionado diretamente com a saúde do idoso (apud LIMA-COSTA; VERAS, 2003²).

\section{5 $O$ restaurante popular de Londrina}

Os Restaurantes Populares são estabelecimentos administrados pelo poder público, e que se definem pela elaboração e comercialização de refeições saudáveis, nutricionalmente balanceadas, proveniente de processos seguros, constituídas com produtos regionais, a preços acessíveis, servidas em locais apropriados e confortáveis, de forma a garantir a dignidade ao ato de se alimentar (MDS, 2004).

A refeição oferecida à população que se alimenta fora do domicílio apresenta cardápios variados, mantendo o equilíbrio entre os nutrientes (carboidratos, proteínas, lipídios, fibras, vitaminas, sais minerais e água) em uma mesma refeição, tornando possível seu máximo aproveitamento pelo organismo, minimizando os riscos de agravos à saúde decorrentes de uma alimentação inadequada (MDS, 2004).

Cada unidade dos Restaurantes Populares fornece um mínimo de mil refeições por dia, sempre respeitando as características culturais e hábitos alimentares da região. O órgão responsável pelo programa orienta a cobrança de um preço acessível à população de baixa renda da região, e que a refeição seja adequada e saudável, não ultrapassando o valor de R \$ 2,00 (MDS, 2004).

Um problema comum aos idosos é a instabilidade financeira, pois a maioria conta financeiramente apenas com sua aposentadoria, fazendo com que o consumo de alimentos seja limitado ao essencial (RELVAS, 2006).

Os Restaurantes Populares são geralmente implantados em regiões centrais, próximos a locais que tenham transporte coletivo e que possuam grande fluxo de trabalhadores de baixa renda, formais e/ou informais, idosos, desempregados e estudantes. A implantação também pode ser realizada em regiões periféricas e metropolitanas, onde há maior concentração de população em situação de risco ou vulnerabilidade alimentar e nutricional (MDS, 2014).

2 LIMA-COSTA, M. F.; VERAS, R. Saúde pública e envelhecimento. Cadernos de Saúde Pública, v.19, n. 3, p.700-7001, 2003. 
A localidade pode ser um fator interferente, pois as pessoas mais velhas sofrem dificuldades em adquirir alimentos, tendo conhecimento de que a velhice dificulta ainda mais as atividades comuns e rotineiras. Também se pode considerar como dificuldades enfrentadas pelos idosos, quanto à limitação, o uso de meios de transporte e a necessidade de ajuda de terceiros, o que influencia nos seus hábitos alimentares (RELVAS, 2006).

A promoção e o desenvolvimento de atividades de educação alimentar e cuidados com a saúde, fazem parte do exercício realizado pelos Restaurantes Populares, estímulando a sociedade à combate a fome e adotar hábitos alimentares saudáveis, contribuindo para a prevenção e o combate de uma série de doenças relacionada à alimentação inadequada, como obesidade, hipertensão e diabetes, entre outras (MDS, 2014).

O Restaurante Popular de Londrina, batizado com o nome de Leonel Brizola, foi inaugurado em 6 de julho de 2012, com capacidade para servir mil refeições diárias a um preço ao consumidor de $\mathrm{R} \$ 1,50$, sendo que a prefeitura de Londrina subsidia outros $\mathrm{R}$ \$ 5,20 para cobrir os custos de $\mathrm{R} \$ 6,70$ de cada refeição (MDS, 2014).

Conforme o Ministério do Desenvolvimento Social e Combate à Fome (MDS), a unidade instalada em uma área de $1,2 \mathrm{mil} \mathrm{m}^{2}$ é resultado de convênio firmado entre o MDS e a prefeitura de Londrina, Paraná, em 2010. O MDS investiu R \$ 1,4 milhão e o governo da cidade investiu outros R \$ 280 mil. O Restaurante está localizado à Rua Professor João Cândido, 10 (esquina com Avenida Dom Geraldo Fernandes) - Londrina (PR), com funcionamento de segunda a sexta-feira, das 11 h às 14h (MDS, 2014). A Figura 9.2 mostra a fachada da instalação.

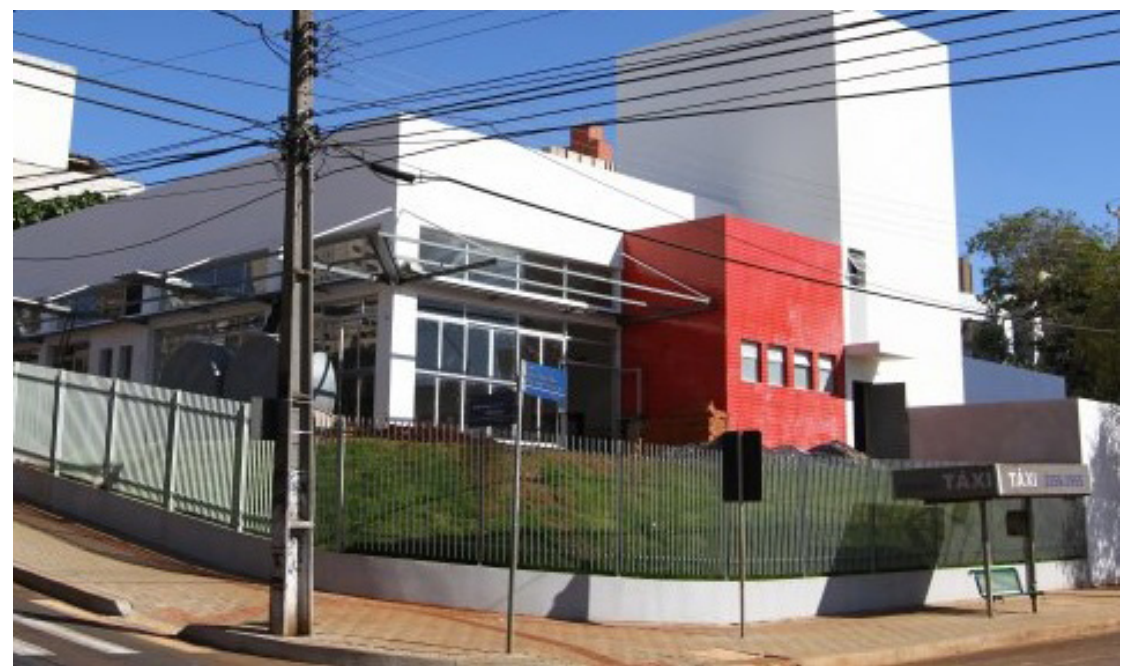

Fonte: Autoria própria.

Figura 9.2 Prédio do Restaurante Popular de Londrina 
O restaurante esteve fechado por seis meses em função de problemas no processo licitatório para o fornecimento das refeições, mas reabriu em 13 de janeiro de 2014. Atualmente, a empresa responsável pela preparação e disponibilização das refeições é a Sepat Multi Service, de Joinville (RESTAURANTE POPULAR..., 2014).

\section{MATERIAIS E MÉTODOS}

Quanto à sua natureza, esta pesquisa é de caráter aplicado, visto que objetiva gerar conhecimentos para aplicação prática dirigidos à solução de problemas específicos, envolvendo verdades e interesses locais, como esclarece Vergara (2004). Em relação à forma de abordagem, vale-se da pesquisa quantitativa, pois se deseja traduzir, em números, opiniões e informações para classificá-las e analisá-las por meio de ferramentas estatísticas (SANTOS, 2004). Do ponto de vista de seus objetivos, como aborda Mattar (2002), é uma pesquisa de cunho descritivo, uma vez que se pretende descrever as características de alimentação dos idosos residentes em Londrina. Para tanto, a coleta de dados será executada através de observação direta.

\subsection{Procedimento de coleta}

Nos dias 7, 8 e 10 de abril de 2014, durante o horário de atendimento do Restaurante Popular de Londrina (11:00 às 14:00 horas), realizou-se entrevistas para coleta de dados com pessoas idosas (idade igual ou superior a 60 anos), abordando individual e aleatoriamente ambos os gêneros. Os questionários foram aplicados pela própria pesquisadora, e as fotografias foram tiradas por uma auxiliar, visto que ambas ficavam posicionadas no local de descarte de resíduos orgânicos aguardando a chegada de um idoso.

Antes de iniciar a pesquisa, tirava-se uma foto da bandeja que continha as porções dos alimentos a serem servidos no suposto dia, para que pudesse empregá-la como modelo padrão, e posteriormente realizar comparações (Figura 9.3). A bandeja era de material inoxidável e possuía seis espaços de tamanhos diferenciados e preestabelecidos, deixando os alimentos separados por porções.

A aplicação da pesquisa ocorreu com o auxílio de um questionário padrão com três perguntas fechadas: uma sobre o sexo, uma sobre a faixa etária e uma sobre qual a principal refeição do dia, sendo o questionário elaborado em função dos objetivos da presente pesquisa. Para questão de controle, cada questionário permanecia adesivado com um número referente ao mesmo, e quando se iniciava a entrevista, retirava-se o adesivo e o colava na bandeja, tirava-se uma foto desta e recolocava-se o adesivo no questionário, grampeando-o na folha. 


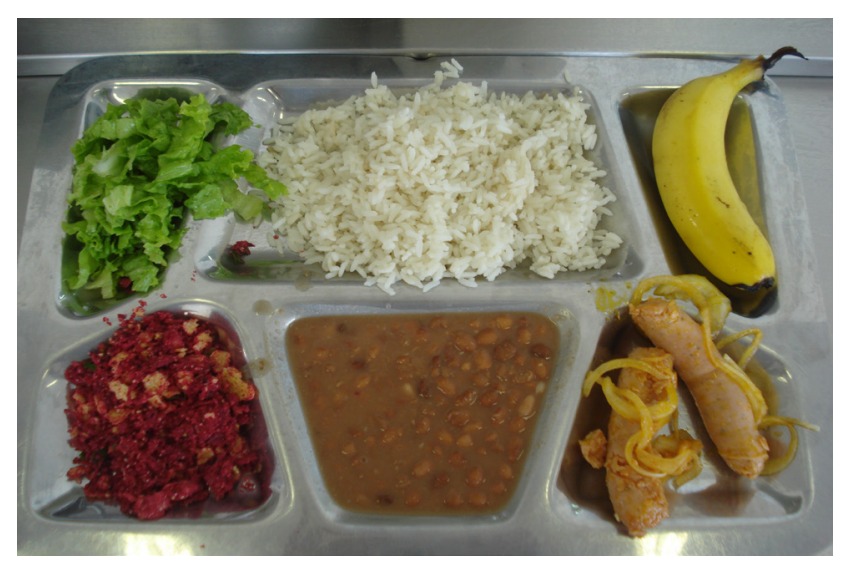

Figura 9.3 Refeição servida pelo Restaurante Popular

Ao entrar no estabelecimento, é solicitado aos consumidores para que peguem uma bandeja e os utensílios disponíveis. Os alimentos ficam dispostos em um buffet, onde funcionárias posicionadas atrás de um alimento específico serve a porção estabelecida. É imposto pelo Restaurante Popular que, ao término da refeição, cada pessoa é responsável por levar sua bandeja aos locais de descarte de resíduos orgânicos e recicláveis, e ao local de lavagem e higienização dos utensílios utilizados.

Quando se avistava uma pessoa que portava características de idade igual ou superior ao requerido pela pesquisa, realizava-se a abordagem e, de modo sutil e respeitoso, perguntava-se a idade da mesma. Caso houvesse o enquadre da idade requerida, pedia-se gentilmente a colaboração na participação da pesquisa. Caso o idoso aceitasse, eram realizadas as perguntas contidas no questionário, enquanto tirava-se uma foto somente da bandeja (Figura 9.4).

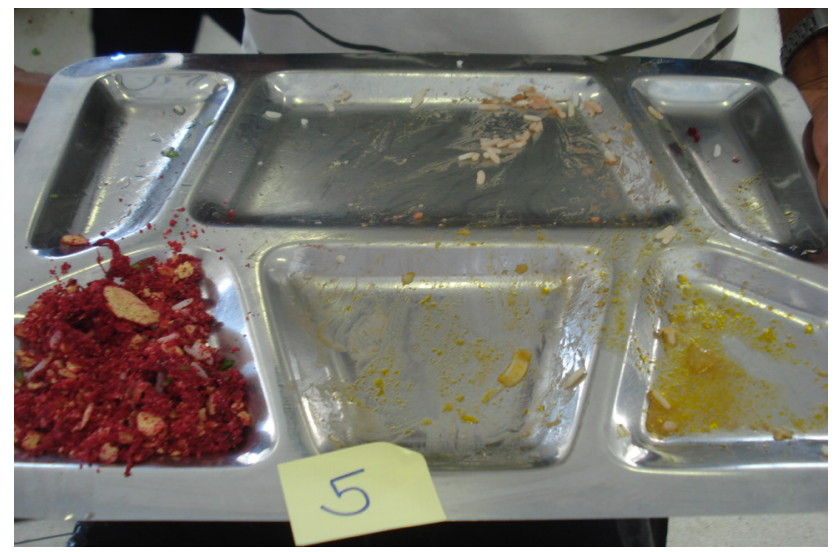

Figura 9.4 Refeição consumida pela pessoa idosa 
Uma vez fotografada a bandeja com alimentos deixados ou totalmente consumido pelo idoso, realizou-se a comparação da mesma com a foto da bandeja modelo, a qual continha a refeição completa servida no dia. Com a observação de determinada quantidade de alimento subtraído, conseguiu-se estimar o tamanho da porção consumida, resultando, assim, na informação das porções consumidas por cada idoso.

Os dados obtidos foram tabulados no software Excel 2010 e, a partir dos resultados, foram criados histogramas, gráficos e tabelas para facilitar a visualização e, consequentemente, melhor compreensão dos dados.

\subsection{Análise dos dados}

Os dados são coletados para dois propósitos mais amplos: 1) descobrir, e para tal utiliza-se a estatística descritiva, e 2) testar, e para tal utiliza-se a estatística inferencial, conforme Mattar (2002).

Os métodos descritivos têm o objetivo de proporcionar informações sumarizadas dos dados contidos no total de elementos da amostra estudada. Métodos descritivos compreendem: medidas de posição, que servem para caracterizar o que é típico do grupo; medidas de dispersão com o propósito de medir como os indivíduos estão distribuídos no grupo; e medidas de associação, que servem para medir o nível de relacionamento existente entre duas ou mais variáveis (DANCEY; REIDY, 2006).

Esta pesquisa vale-se das medidas de posição, que servem para caracterizar o que é típico no grupo, e sua representação gráfica. Essas medidas compreendem as medidas de tendência central, conforme Dancey e Ready (2006).

A média é a soma de todos os valores da amostra, dividida pela quantidade de amostras. Os dados comumente mostram algum grau de tendência central, com a maioria das respostas distribuídas próximas da média ou valor central.

A moda, que tem por objetivo identificar o valor ou categoria que ocorre com maior frequência, é o valor que representa o pico mais alto no gráfico de distribuição. É a medida apropriada de tendência central para dados nominais.

Por meio da mediana, busca-se o valor da variável correspondente ao elemento central da distribuição. A mediana é o valor abaixo (e acima) do qual recai metade dos valores na distribuição da amostra, constituindo a média dos dois valores centrais de uma amostra.

As representações gráficas permitem uma interpretação rápida dos dados e facilitam a visualização de possíveis associações entre variáveis. Para apresentação visual dos dados, utilizou-se o histograma, o gráfico e a tabela. 


\section{RESULTADOS}

Os dados foram levantados junto a 286 frequentadores do Restaurante Popular de Londrina, entre os dias 7, 8 e 10 de abril de 2014, utilizando como forma de coleta um questionário padrão e a quantidade de alimento deixada na bandeja ao final da refeição de cada idoso. As bandejas foram fotografadas, com a anuência dos entrevistados, para posterior análise.

Das 286 coletas, foram utilizadas 196. Nas demais, ou o respondente não se enquadrava no perfil desejado, ou a foto não permitiu a análise das porções de alimentos descartados.

A distribuição dos respondentes por gênero apresentou 107 respondentes do sexo masculino e 89 do sexo feminino. O Gráfico 9.1 mostra essa distribuição em porcentagem.

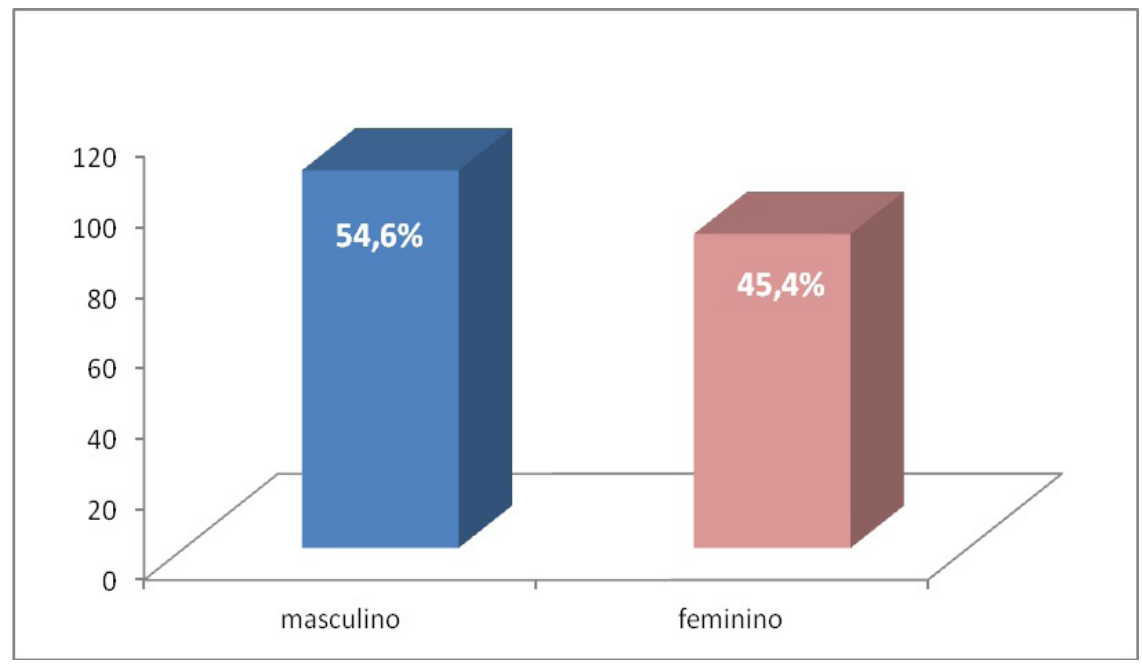

Gráfico 9.1 Distribuição percentual dos respondentes por gênero

Em relação à idade dos respondentes, esses foram distribuídos em quatro grupos, lembrando que foram consideradas idosas as pessoas com 60 anos completos ou mais. O grupo 1 foi composto de pessoas entre 60 e 69 anos; o grupo 2, entre 70 e 79 anos; o grupo 3, entre 80 e 89 anos; e o grupo 4, por pessoas com idade superior a 90 anos.

O Gráfico 9.2 ilustra essa distribuição etária dos respondentes, onde os respondentes do grupo 2 são prevalecentes, com quase $58 \%$ do total, seguido do grupo 1 , com $27,5 \%$. 


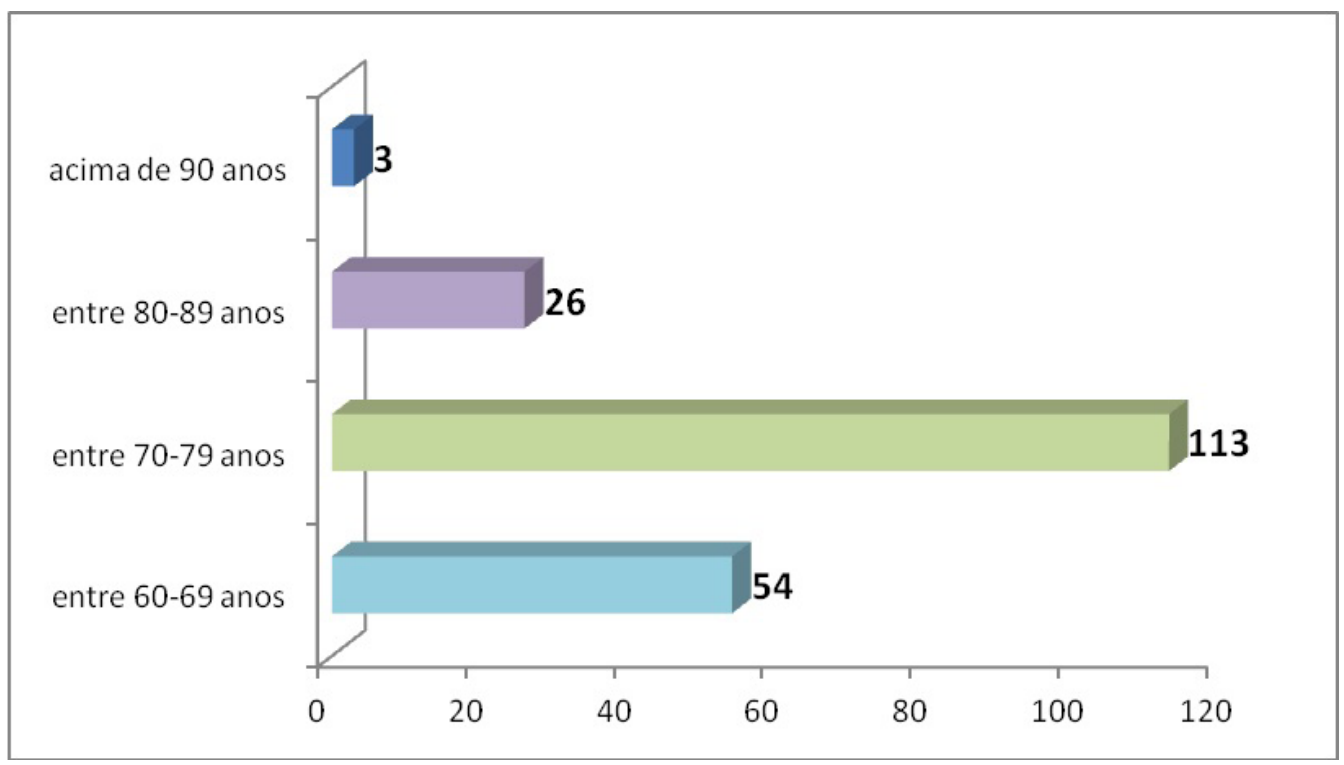

Gráfico 9.2 Distribuição numérica dos respondentes por faixa etária

As informações etárias, quando cruzadas por gênero, apresentaram uma distribuição bastante equitativa nos grupos 1 e 2, mas à medida que a idade avança, a amostra demonstrou uma prevalência para o sexo masculino, conforme ilustra o Gráfico 9.3.

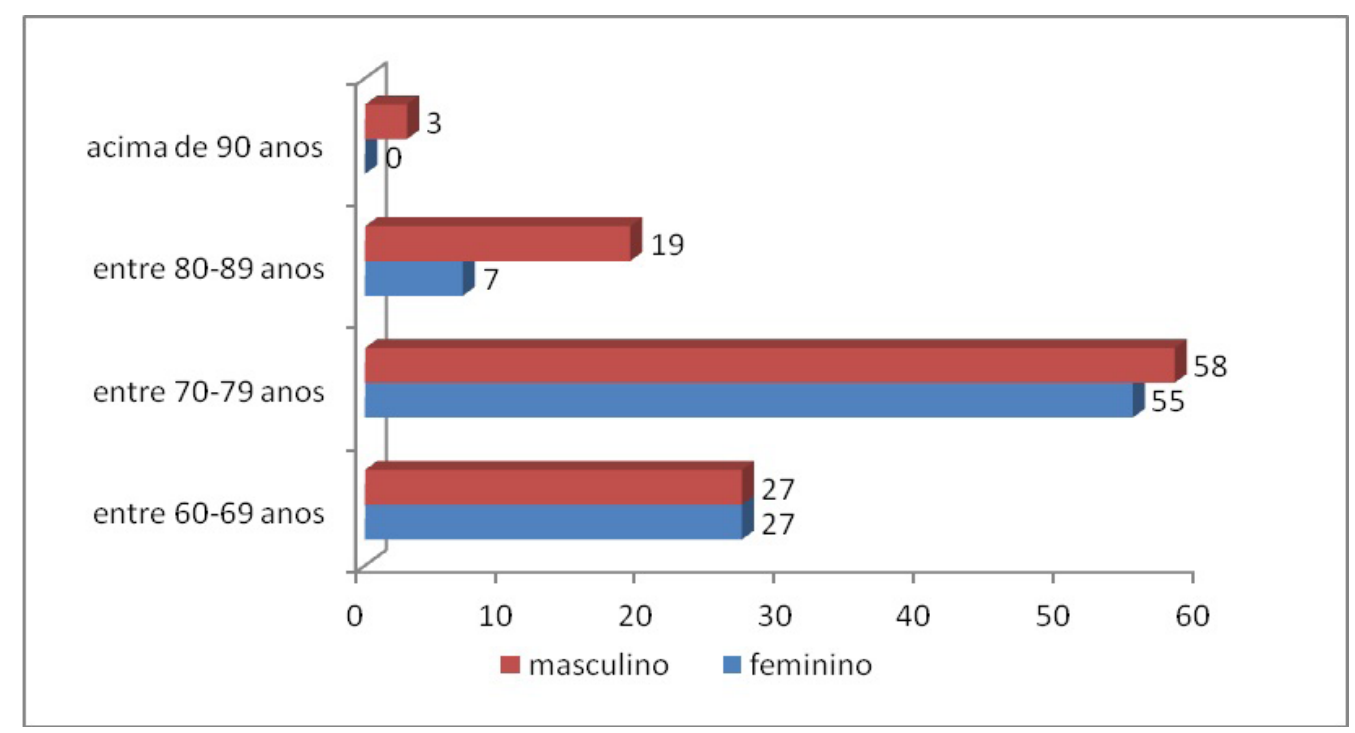

Gráfico 9.3 Relação entre gênero e faixa etária dos respondentes 
Para que fosse possível estimar as porções de alimentos consumidos pelas pessoas idosas, o presente trabalho teve como direcionamento a pirâmide alimentar. De acordo com o cardápio estabelecido pelo Restaurante Popular de Londrina e fornecido aos respondentes, os alimentos estão distribuídos em cinco grupos distintos, de acordo com os níveis estabelecidos na pirâmide alimentar, estando presente o primeiro nível, composto pelo grupo 1 dos cereais, pães, tubérculos e raízes; o segundo nível, composto pelo grupo, 2 das hortaliças, e o grupo 3, das frutas; e o terceiro nível, composto pelo grupo 5, das carnes, e o grupo 6, das leguminosas. Os demais níveis e grupos não empregados são justificados pela ausência dos mesmos e por ser inaveriguável a quantidade contida no cardápio fornecido, tal como a quantidade de gordura presente.

A média de consumo de alimentos pertencentes ao grupo 1 é de 1,8 porções, porém, o Histograma 9.1 aponta que a frequência de maior incidência é de duas porções com presença superior a $61 \%$, enquanto somente um dos investigados consumiu meia porção.

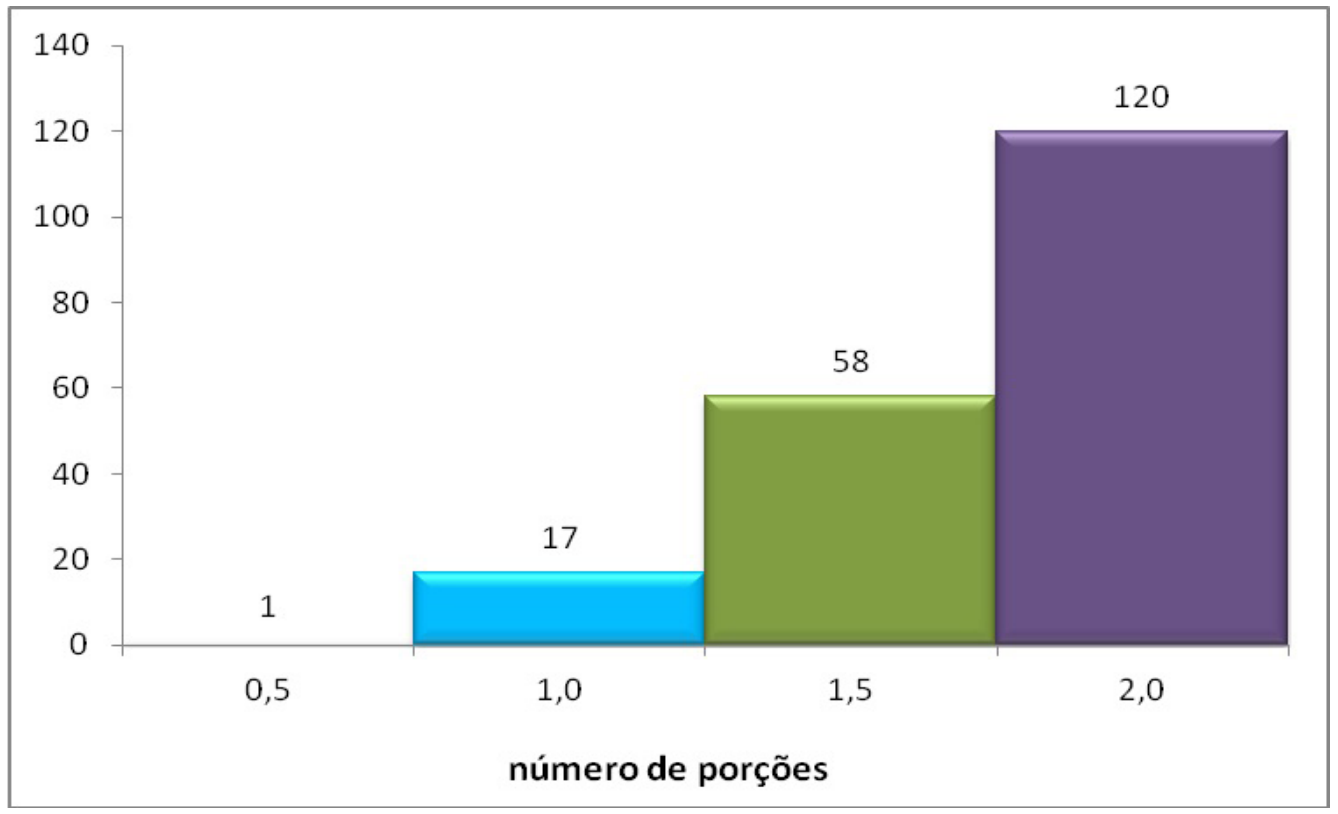

Histograma 9.1 Frequência de consumo por quantidade de porções de alimentos do grupo 1

Quando comparado à quantidade de porções de alimentos do grupo 1 entre os gêneros, observa-se um equilíbrio, não havendo distinção em relação às quantidades ingeridas deste grupo considerando o comportamento de homens e mulheres. O Gráfico 9.4 revela essa distribuição percentual. 


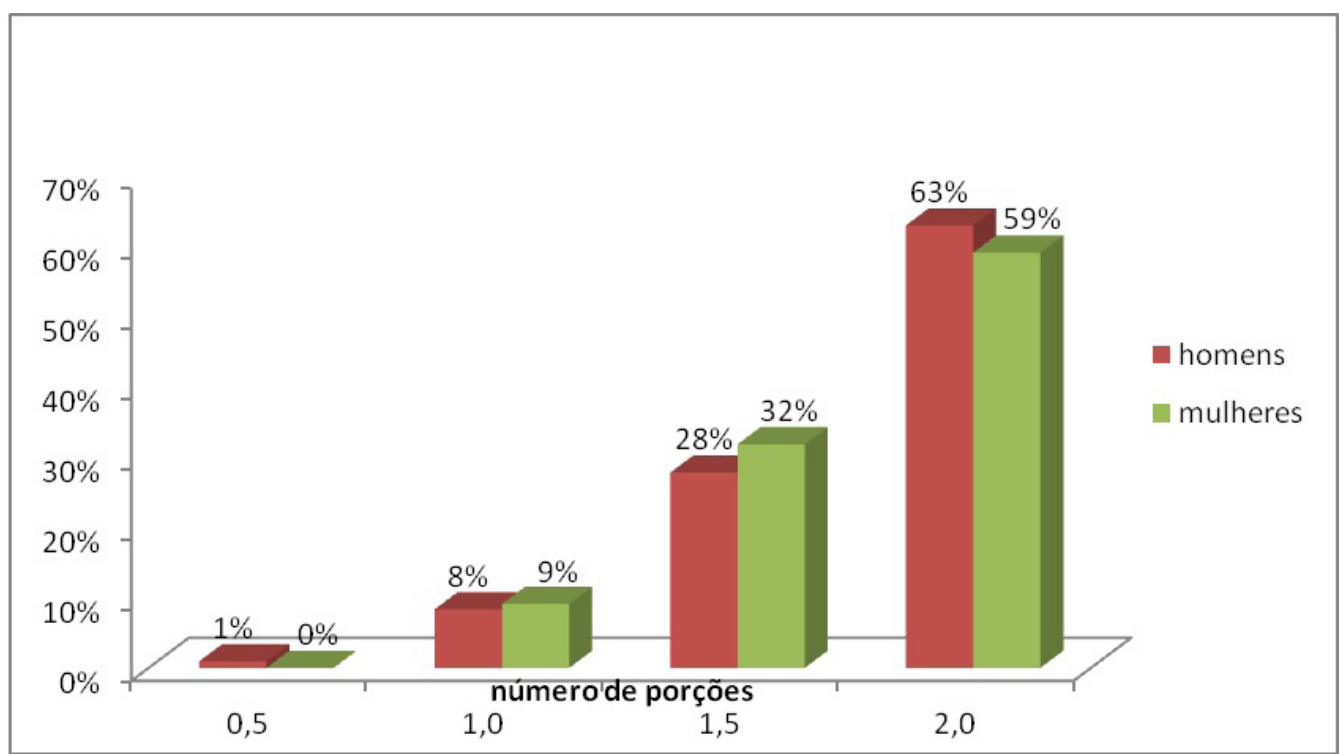

Gráfico 9.4 Distribuição percentual de porções de alimentos do grupo 1 em relação ao gênero

Similar comparação é feita agora, considerando a quantidade de porções de alimentos do grupo 1 em relação à idade dos pesquisados.

Tabela 9.1 Distribuição de porções de alimentos do grupo 1 em relação à idade

\begin{tabular}{ccccc}
\hline \multirow{2}{*}{ Idade } & \multicolumn{5}{c}{ Quantidade de porções } \\
\cline { 2 - 5 } & $\mathbf{0 , 5}$ & $\mathbf{1 , 0}$ & $\mathbf{1 , 5}$ & $\mathbf{2 , 0}$ \\
\hline entre 60-69 anos & 0 & 1 & 22 & 31 \\
entre 70-79 anos & 1 & 9 & 30 & 73 \\
entre 80-89 anos & 0 & 6 & 6 & 14 \\
acima de 90 anos & 0 & 1 & 0 & 2 \\
TOTAL & 1 & 17 & 58 & 120 \\
\hline
\end{tabular}

A Tabela 9.1 aponta uma predominância para o consumo de duas porções de alimentos desse grupo em qualquer grupo de idade, perfazendo um percentual de $61 \%$ de todos os respondentes que optaram pelo consumo de duas porções. Se considerado o total de pessoas que consumiram pelo menos uma porção e meia, esse percentual totaliza $91 \%$ da amostra pesquisada.

Os alimentos que constituem o segundo nível são o grupo 2, das hortaliças, e o grupo 3, das frutas, que embora tenham sido mensuradas separadamente, para efeito de apresentação dos resultados, tiveram suas porções de consumo somadas 
por fazerem parte do mesmo nível classificatório da pirâmide alimentar. A média de consumo para esses alimentos foi de 2,7 porções por pessoa, mas quando feita a estratificação por gênero, constata-se que homens apresentam uma média de consumo total $16 \%$ maior que as mulheres.

O Gráfico 9.5 ilustra a distribuição de porções de consumo dos alimentos dos grupos 2 e 3 separados por gênero.

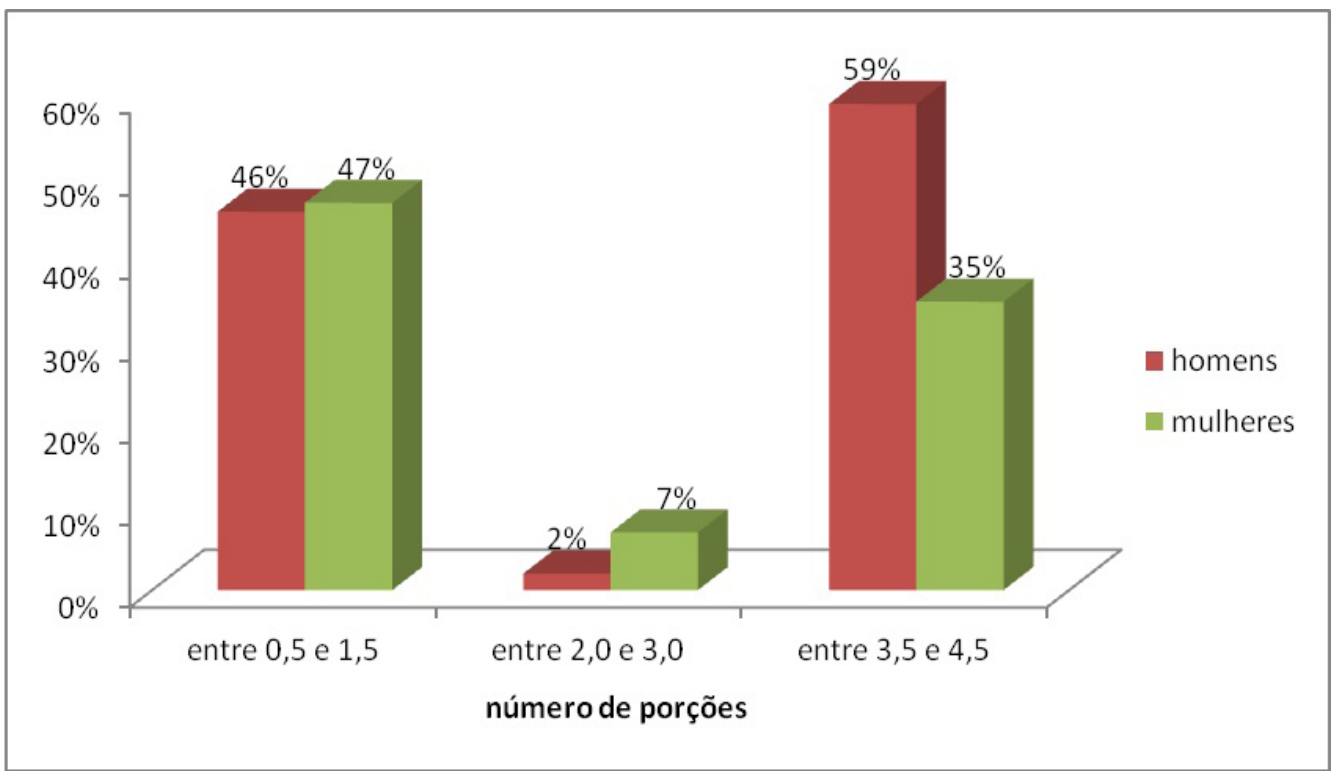

Gráfico 9.5 Distribuição percentual de porções de alimentos dos grupos 2 e 3 em relação ao gênero

O Histograma 9.2 ilustra as quantidades de porção que são mais consumidas, deixando transparecer a existência de dois grupos: aqueles que apreciam o consumo maior de frutas e hortaliças, perfazendo $48 \%$ do total e cuja média é de 3,9 porções, enquanto um segundo grupo, de mesma dimensão, tem um consumo médio de 1,4 porções por pessoa.

A relação da quantidade de porções consumidas de alimentos dos grupos 2 e 3, estratificadas por idade é apresentado na Tabela 9.2.

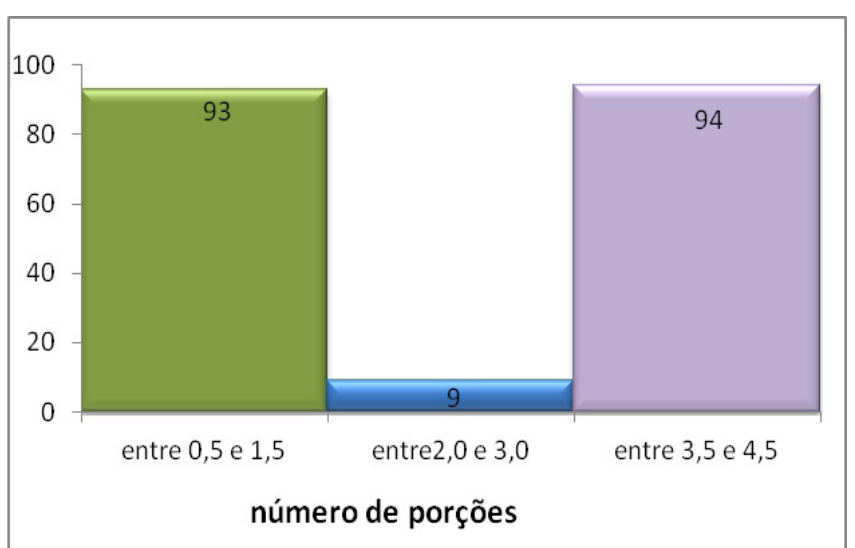

Histograma 9.2 Frequência de consumo por quantidade de porções de alimentos dos grupos 2 e 3 . 
Tabela 9.2 Distribuição de porções de alimentos dos grupos 2 e 3 em relação à idade

\begin{tabular}{cccc}
\hline \multirow{2}{*}{ Idade } & \multicolumn{3}{c}{ Quantidade de porções } \\
\cline { 2 - 4 } & entre 0,5 e 1,5 & entre 2,0 e 3,0 & entre 3,5 e 4,5 \\
\hline entre 60-69 anos & 26 & 4 & 24 \\
entre 70-79 anos & 57 & 4 & 52 \\
entre 80-89 anos & 8 & 1 & 17 \\
acima de 90 anos & 2 & 0 & 1 \\
TOTAL & 93 & 9 & 94 \\
\hline
\end{tabular}

Também esses números apontam uma distribuição que respeita o apreciar mais ou menos o consumo de alimentos elencados nos grupos 2 e 3 , independentemente da idade.

Os alimentos que constituem o terceiro nível são os do grupos 5, das carnes e ovos, e do grupo 6, das leguminosas, e, da mesma forma que os alimentos dos grupos 2 e 3, embora os consumos tenham sido mensurados separadamente, para efeito de apresentação dos resultados tiveram suas porções somadas. A média de consumo para esses alimentos foi de 3,6 porções por pessoa.

Quando feita a estratificação por gênero, constata-se pouca diferença entre homens e mulheres, sendo que os primeiros apresentaram, em geral, um consumo ligeiramente superior. O Gráfico 9.6 traz essa distribuição de porções de consumo dos alimentos dos grupos 5 e 6 entre homens e mulheres.

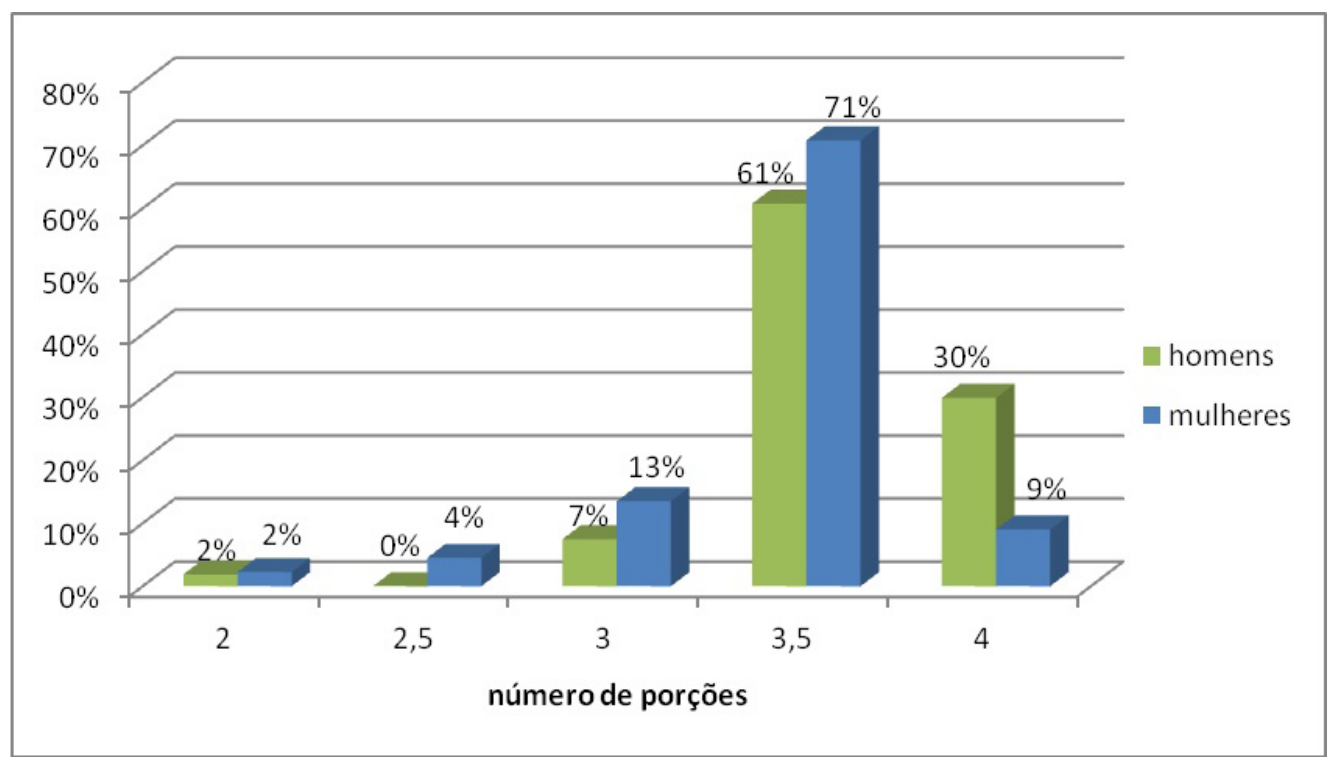

Gráfico 9.6 Distribuição percentual de porções de alimentos dos grupos 5 e 6 em relação ao gênero 
Considerando a quantidade segundo sua frequência, predomina $(65 \%)$ a quantidade de 3,5 de porções, seguida por $20,5 \%$ para a quantidade de quatro porções. O Histograma 9.3 ilustra a distribuição quantitativa dessas porções de alimentos dos grupos 5 e 6 .

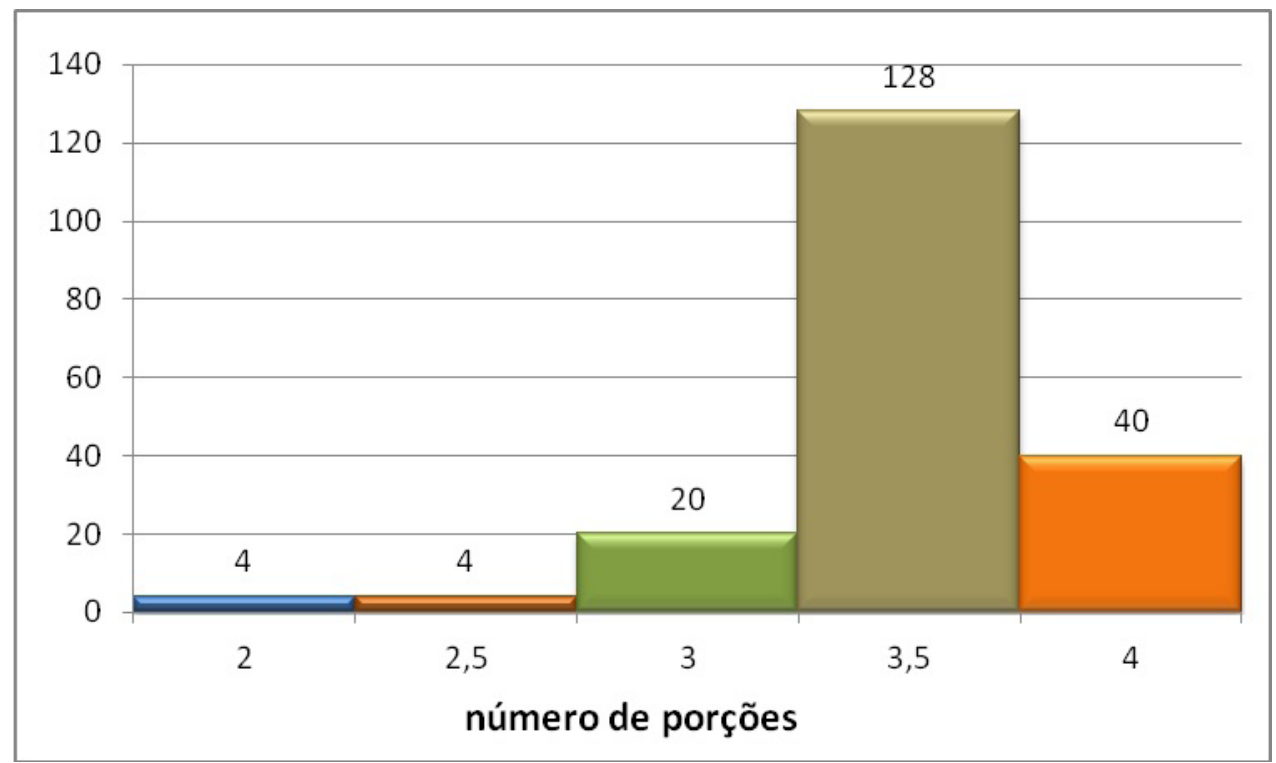

Histograma 9.3 Frequência de consumo por quantidade de porções de alimentos dos grupos 5 e 6

A relação da quantidade de porções consumidas de alimentos dos grupos 5 e 6, estratificadas por idade, é apresentada na Tabela 9.3.

Tabela 9.3 Distribuição de porções de alimentos dos grupos 5 e 6 em relação à idade

\begin{tabular}{cccccc}
\hline \multirow{2}{*}{ Idade } & \multicolumn{5}{c}{ Quantidade de porções } \\
\cline { 2 - 6 } & $\mathbf{2 , 0}$ & $\mathbf{2 , 5}$ & $\mathbf{3 , 0}$ & $\mathbf{3 , 5}$ & $\mathbf{4 , 0}$ \\
\hline entre 60-69 anos & 0 & 2 & 4 & 39 & 8 \\
entre 70-79 anos & 3 & 2 & 10 & 74 & 24 \\
entre 80-89 anos & 1 & 0 & 6 & 12 & 7 \\
acima de 90 anos & 0 & 0 & 0 & 3 & 1 \\
TOTAL & 4 & 4 & 20 & 128 & 40 \\
\hline
\end{tabular}

Os dados mostram que, independente da idade, a preferência de consumo é para 3,5 porções de alimentos pertencentes aos grupos 5 e 6 . 
Philippi et al. (1999) relatam que a pirâmide alimentar é utilizada como instrumento que auxilia nutricionalmente os profissionais da área competente, objetivando promover transformações de hábitos alimentares, visando a saúde global do indivíduo e a prevenção de doenças (apud ACHTERBERG; McDONNELL; BAGBY, 1994³). Dependendo da faixa etária populacional com a qual se trabalha, há a necessidade de alertar sobre os riscos à saúde proveniente do consumo exagerado dos alimentos como óleo, gorduras, açúcares e doces.

Os oito grupos que compõe a pirâmide alimentar são definidos por números de porções diárias para cada grupo. Desse modo, de acordo com Philippi et al. (1999), para cada alimento existe uma quantidade de porções estipuladas para o consumo, assim, sugerem: de cinco a nove porções de pães, cereais, raízes e tubérculos (pães, farinhas, massas, bolos, biscoitos, cereais matinais, arroz, feculentos e tubérculos); de quatro a cinco porções de hortaliças (todas as verduras e legumes); de três a cinco porções de frutas (cítricas e não cítricas); de uma a duas porções de carnes (carne bovina e suína, aves, peixes, ovos, miúdos e vísceras); e uma porção de leguminosas (feijão, soja, ervilha, grão de bico, fava, amendoim).

\section{DISCUSSÃO}

De acordo com os resultados obtidos no presente trabalho, a partir da pesquisa realizada com 196 idosos, a distribuição por gênero apresenta 54,6\% dos respondentes pertencentes ao sexo masculino e $45,4 \%$ ao sexo feminino. A partir do número total de respondentes, a idade que apresentou maior ocorrência (Gráfico 9.2) está entre 70 e 79 anos, seguida pela faixa etária entre 60 e 69 anos.

Quando a variável idade e gênero são cruzadas, o Gráfico 9.3 revela que, após a faixa etária entre 60 e 69 anos, a relação idade é inversamente proporcional ao gênero, sendo notável a prevalência do sexo masculino. Estudos demonstram que a sobressalência da presença do gênero masculino pode ser explicada devido a diversas causas, mas principalmente pelo fato de as mulheres estarem sob os cuidados da família, como os filhos, ou de instituições que prestam serviços à pessoa idosa gratuitamente.

Segundo Relvas (2006), as características para consumo dependem de vários fatores, como o local e o horário da alimentação, local de compra, preparo e consumo, entre outros. Quando a comida é colocada como tema central, as atitudes de comer sozinho ou em grupo, ou realizar a refeição fora do domicílio representam a alteração das necessidades biológicas em sociais, motivadas pelo aumento do número de pessoas que vivem sozinhas e a grande demanda por alimentos prontos para consumo (WOORTMANN, 1986).

3 ACHTERBERG, G; McDONNELL, E.; BAGBY, R. How to putthe food guide into pratice. Journal of American Dietetic Association, Chicago, v. 94, n. 9, p. 1030-1035, 1994. 
O estudo de Silva e Lima (2013) apresenta uma pesquisa com 90 idosos, dos quais apenas $55,5 \%$ foram elencados para o proposto estudo. A caracterização mostrou que mais da metade dos idosos residiam em instituições sem fins lucrativos, eram do sexo feminino, tinham idades entre 80 e 90 anos e tinham de um a dois filhos. A grande maioria era composta por solteiro(as), separados(as), viúvos(as) ou divorciados(as), 1/3 era analfabeto(a), enquanto o restante tinha algum grau de escolaridade.

Dentre alguns fatores associados com a probabilidade de uma pessoa comer fora do domicílio estão: a localidade do domicílio, pois os residentes em áreas urbanas constituem $42,7 \%$ daqueles que comem fora do domicílio, mas, para os residentes em áreas rurais, essa porcentagem é $27,2 \%$; comparação entre ambos os sexos, pois as pessoas que comem fora são $36,3 \%$ do sexo feminino, contra $44,3 \%$ do sexo masculino; a descendência étnica entre brancos, amarelos, pretos e pardos, com proporção dos que comem fora do domicílio em 43,1\%, 39,3\%, $37,8 \%$ e $37,3 \%$, respectivamente (HOFFMANN, 2013).

O comportamento de consumo de alimentos do primeiro nível apresentou frequência de maior incidência no consumo de duas porções do grupo 1, conferindo quantidade superior a $61 \%$ dos respondentes. Essa maioria predominante demonstra equivalência quando comparados ambos os sexos e entre os grupos de idades.

A quantidade de porções estipuladas para o consumo do grupo 1 é definido por cinco porções, no mínimo, a nove porções, no máximo, de pães, cereais, raízes e tubérculos (pães, farinhas, massas, bolos, biscoitos, cereais matinais, arroz, feculentos e tubérculos), segundo Philippi et al. (1999), caracterizando o consumo dentro do recomendado.

Os alimentos que possuem maior fonte de energia são os carboidratos, citados como os mais consumidos pelos idosos em Tinôco et al. (2007), destacando-se o arroz branco e o pão francês como os mais preferidos. O arroz branco e o feijão possuem lugares de destaque na alimentação dos idosos, por caracterizarem maior consumo, visto que tais alimentos são conceituados como base da alimentação do brasileiro (LOPES et al., 2010; FREITAS; PHILIPPI; RIBEIRO, 2011).

Constituindo o comportamento alimentar do segundo nível, estão empregados somaticamente o grupo 2, das hortaliças, e o grupo 3, das frutas, que apresentaram $48 \%$ de consumo, cuja média é de 3,9 porções, o que exprime maior apreciação, visto que um segundo grupo, de mesma dimensão, tem um consumo médio de 1,4 porções por pessoa. As mesmas proporção e preferência se repetem em relação à idade, mas o gênero masculino obteve relevância e exibiu média de consumo total $16 \%$ maior que as mulheres.

A falta da percepção sensorial causada por problemas crônicos e outras limitações podem ter gerado diferença de apreciação entre os idosos. Segundo Santos 
(2003), um fator complicador no consumo alimentar dos idosos é a questão da percepção sensorial, visto que, após os 60 anos, existe uma tendência de perdas sensoriais de determinados alimentos devido à doenças, medicamentos e cirurgias.

De acordo com Philippi et al. (1999), as porções estabelecidas variam entre quatro porções, no mínimo, a cinco, no máximo, de hortaliças (todas as verduras e legumes) e três porções, no mínimo, a cinco, no máximo, de frutas (cítricas e não cítricas), o que entra em concordância com a média de 3,9 porções consumidas pelos frequentadores pesquisados do Restaurante Popular de Londrina.

A relevância de maior consumo do grupo 2 e 3 por parte do sexo masculino causa contradição com outros estudos apontados. A frequência de consumo regular de frutas, legumes e verduras em indivíduos do sexo feminino que apresentam 60 anos ou mais, das classes A e B, ex-fumantes e não sedentários, possui maior prevalência de consumo de frutas, legumes e verduras. (NEUTZLING et al., 2009). Bezerra (2013) menciona, em seu estudo, que os homens apresentaram médias totais de consumo superiores às mulheres para a maioria dos grupos de alimentos, com exceção de verduras, frutas e sopas.

Dentre os alimentos pertencentes ao terceiro nível, estão empregados de forma agregada o grupo 5, das carnes e ovos, e o grupo 6, das leguminosas. A média de consumo revela 3,6 porções por pessoa e, quando restringido ao gênero, os homens apresentam, mais uma vez, consumo ligeiramente superior em comparação com as mulheres. A preferência de consumo é de $65 \%$ para a quantidade de 3,5 de porções, seguido por $20,5 \%$ para quatro porções, sendo que, independente da idade, a prevalência será de 3,5 porções.

O consumo das porções do grupo 5 e 6 estão excedendo o limite de consumo diário estabelecido pela pirâmide alimentar, que estipula uma porção, no mínimo, e duas, no máximo, de carnes (carne bovina e suína, aves, peixes, ovos, miúdos e vísceras), e uma porção de leguminosas (feijão, soja, ervilha, grão de bico, fava, amendoim). As recomendações das porções visam atender às recomendações de nutrientes e vitaminas a serem consumidos e, ao consumir um número de porções além do estipulado, existe a possibilidade de exceder o total energético determinado da dieta padrão e influenciar negativamente na qualidade da dieta (PHILIPPI et al. 1999).

O Gráfico 9.7 compara, através do gênero, a ideal distribuição de porções de consumo de todos os grupos alimentares em relação ao consumo real da pessoa idosa.

Embora com algumas variações, os dados apontam não haver uma clara distinção de consumo de alimentos entre homens e mulheres, considerando a amostra trabalhada, e tampouco uma variação relevante no comportamento de consumo em relação à idade dos respondentes. 


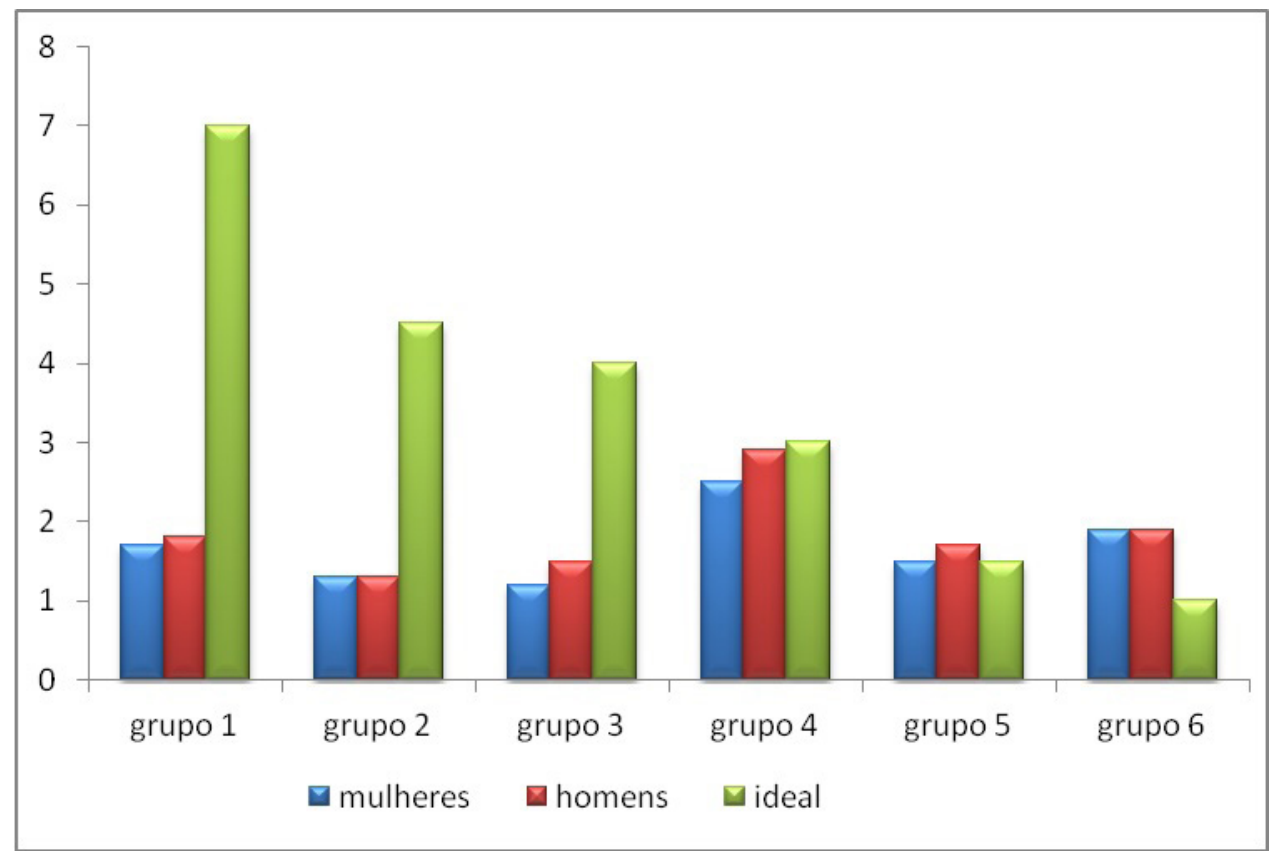

Gráfico 9.7 Distribuição percentual de porções de alimentos que o idoso deveria consumir em relação ao quanto estão consumindo, por gênero

Quando comparados os consumos realizados por grupo de alimentos com o consumo considerado ideal, consideradas as quantidades médias, há um nítido descompasso, para menos, no consumo de alimentos dos grupos 1, 2 e 3, ou seja, alimentos como cereais, tubérculos, hortaliças e frutas são consumidos em porções significativamente abaixo do recomendado.

Em relação aos alimentos do grupo 5, carnes e ovos, esses são consumidos em valores que atendem aos valores estipulados como adequados, mas os alimentos do grupo 6, em compasso com outro estudo associado ao hábito alimentar regionalizado e cultural (BEZERRA, 2013), são consumidos em quantidades superiores àquelas adequadas, prevalecendo o consumo do feijão e do arroz, deixando clara a predominância dos hábitos alimentares tradicionais estabelecidos no Brasil.

\section{CONCLUSÃO}

Resgatando a questão central, o estudo priorizou identificar a ingestão alimentar dos idosos da cidade de Londrina, ficando restrito ao que come o idoso em sua refeição principal, sendo ela o almoço realizado no Restaurante Popular. 
Com a investigação, pôde-se observar que, de acordo com a avaliação das fotografias e com o auxílio do questionário, os alimentos que representaram maior consumo foram os pertencentes ao primeiro nível, composto pelo grupo 1, dos cereais, tubérculos e raízes, e os alimentos do terceiro nível, composto pelo grupo 5 , das carnes e ovos, e pelo grupo 6, das leguminosas. Os dados apontam que o hábito alimentar evidenciado é definido devido aos aspectos culturais e regionais empregados ao longo dos anos vividos, gerando características peculiares.

A despeito das quantidades de alimentos consumidos de cada um dos grupos, ficou patente a necessidade de uma reeducação no comportamento alimentar que privilegie um maior consumo de alimentos como frutas e verduras, em detrimento do consumo de leguminosas.

Desse modo, para que os idosos vivenciem um envelhecimento próspero, é necessário que tenham consciência da importância da realização de práticas de vida saudáveis para garantirem uma qualidade de vida superior.

Sob o ponto de vista acadêmico, os resultados obtidos não podem ser generalizados para toda a população, pois a pesquisa proposta tem como limitação o caráter não probabilístico do método de amostragem utilizado. Porém, esta pesquisa merece destaque pelo fato de trazer informações relevantes para um conjunto significativo da população, o que se traduz em interesse da mídia devido, principalmente, à carência de pesquisas com esse enfoque.

Outra limitação da pesquisa deve-se ao fato de não ter sido possível ter acesso aos dados de consumo de alimentos próprio para a pessoa idosa. Dessa forma, foi utilizada uma tabela de consumo genérica. Uma sugestão de pesquisa futura deveria considerar não só o consumo próprio para a idade, mas também a distinção de consumo entre homens e mulheres, uma vez que o gênero determina prioridades distintas a ambos.

Por fim, é oportuno que outras pesquisas acadêmicas sejam realizadas para que possam contribuir e acrescentar maiores informações sobre o comportamento alimentar do idoso, com o intuito de se obter uma base sólida de conhecimentos.

\section{REFERÊNCIAS}

ABREU, E. S. et al. Alimentação mundial - uma reflexão sobre a história. Saúde Soc., São Paulo, v. 10, n. 2, p. 3-14, ago-dez. 2001.

ACEVEDO, C. R. Perfil do consumidor maduro em viagens de lazer. 1998. Tese (Doutorado em Administração de Empresas) - Fundação Getúlio Vargas, São Paulo, 1998.

ACUÑA K.; CRUZ, T. Avaliação do estado nutricional de adultos e idosos e situação nutricional da população brasileira. Arq. Bras. Endocrinol. Metab., v. 48, n. 3, p. 345, jun. 2004. 
ALMEIDA, I. C. et al. Hábitos alimentares da população idosa: padrões de compra e consumo. In: Seminários em Administração (SEMEAD), 13, São Paulo: USP, 2010. Disponível em: <http://www.ead.fea.usp.br/semead/13semead/resultado/ trabalhosPDF/867.pdf>. Acesso em: 17 jun. 2013.

BEZERRA, I. N. et al. Consumo de alimentos fora do domicílio no Brasil. Revista de Saúde Pública, v. 47, (Supl. 1), p. 200-2011. 2013.

BRASIL. Ministério da Saúde. Alimentação saudável para a pessoa idosa: um manual para profissionais de saúde. Brasília: Ministério da Saúde, 2009.

CAMARGOS, M. C. S.; PERPÉTUO, I. H. O.; MACHADO, C. J. Expectativa de vida com incapacidade funcional em idosos em São Paulo, Brasil. Rev. Panam. Salud. Publica, v. 17, n. 5, p. 379-86, 2005.

CASOTTI, L. À mesa com a família: um estudo do consumidor de alimentos. Rio de Janeiro: Mauad, 2002.

CATÃO, M. H. C. V.; XAVIER, A. F. C.; PINTO, T. C. A. O impacto das alterações do sistema estomatognático na nutrição do idoso. Revista Brasileira de Ciências da Saúde, Campinas, v. 9, n. 29, p. 73-78, 2011.

CERVATO, A. M. et al. Educação nutricional para adultos e idosos: uma experiência positiva em Universidade Aberta para a Terceira Idade. Revista de Nutrição, Campinas, v. 18, n. 1, jan-fev. 2005.

DANCEY, C.; REIDY, J. Estatística sem matemática. Porto Alegre: Artmed, 2006

FREITAS, A. M. P.; PHILIPPI, S. T.; RIBEIRO, S. M. L. Listas de alimentos relacionadas ao consumo alimentar de um grupo de idosos: análises e perspectivas. Revista Brasileira de Epidemiologia, São Paulo, v. 14, n. 1, p. 161-177, 2011.

HOFFMANN, R. Comparando a alimentação dentro e fora do domicílio, no Brasil, em 2008-2009. Segurança Alimentar e Nutricional, Campinas, v. 20, n. 1, p. 1-12, 2013.

IBGE - Instituto Brasileiro de Geografia e Estatística. Censo demográfico 2007. Disponível em: <www.ibge.gov.br/censo>. Acesso em: 29 jun. 2013.

Censo demográfico 2010: Distribuição da população por sexo segundo os grupos de idade, 2010. Disponível em: <www.ibge.gov.br/censo>. Acesso em: 29 de Jun. 2013 LIMA-FILHO, D. O. et al. Comportamento alimentar do idoso. Revista de Negócios, Blumenau, v. 13, n. 4, p. 27-39, out.-dez. 2008.

LIMA-FILHO, D. O.; QUEVEDO-SILVA, F.; FOSCACHES, C. A. L. Perfil do consumidor idoso de alimentos no Brasil. Revista de Negócios, v. 33, n. 7, p. 16. 2012.

LONDRINA. Secretaria Municipal do Idoso. Lei no 10.741 , de $1^{\circ}$ de outubro de 2003. Estatuto do Idoso. Jornal Oficial do Município de Londrina, Londrina, PR, 2010.

Secretaria Municipal do Idoso. Perfil da população Idosa de Londrina.

Londrina, 2009.

LOPES, A. F. et al. Perfil antropométrico e alimentar dos participantes do Programa Universidade Aberta à Terceira Idade (UNATI) do Instituto de Biociências de Botucatu. Revista Ciência Extensão, São Paulo, v. 6, n. 1, p. 1-13, 2010. 
MACEDO, T. M. B.; SCHMOURLO, G.; VIANA, K. D. A. L. Fibra alimentar como mecanismo preventivo de doenças crônicas e distúrbios metabólicos. UNI, Imperatriz, v. 2, n. 2, p. 67-77, jan./jul. 2012.

MALTA, D. C. et al. A construção da vigilância e prevenção das doenças crônicas não transmissíveis no contexto do Sistema Único de Saúde. Epidemiol. Serv. Saúde, Brasília, v.15, n. 3, set. 2006 .

MATTAR, F. N. Pesquisa de marketing. São Paulo: Atlas, 2002.

MENDES, M. R. S. S. B. et al. A situação social do idoso no Brasil: uma breve consideração. Acta Paul Enferm., São Paulo, v. 18, n. 4, p. 422, fev. 2005.

MINAYO, M. C. de S. et al. Pesquisa social: teoria, método e criatividade. 16.ed. Petrópolis: Vozes, 1994.

MDS. Ministério do Desenvolvimento Social de Combate à Fome. Manual - Programa Restaurante Popular. Brasília, 2004. Disponível em: <http:// www.mds.gov.br>. Acesso em: 20 jun. 2014.

NEUTZLING, M. B. et al. Fatores associados ao consumo de frutas, legumes e verduras em adultos de uma cidade no Sul do Brasil. Cad. Saúde Pública, Rio de Janeiro, v. 25, n. 11, nov. 2009.

PAZ, A. A.; SANTOS, B. R. L.; EIDT, O. R. Vulnerabilidade e envelhecimento no contexto da saúde. Acta Paul Enferm., Vacaria, v. 19, n. 3, p. 338-42, jun. 2006.

PHILIPPI, S. T. et al. Pirâmide alimentar adaptada: guia para escolha dos alimentos.

Revista de Nutrição, Campinas, v. 12, n. 1, p. 65-80, jan./abr. 1999.

RELVAS, K. Hábitos de compra e consumo de alimentos de idosos nas cidades de São Paulo, Porto Alegre, Goiânia, Recife. 2006. 119 f. Dissertação (Mestrado em Agronegócio) - Programa de Pós-Graduação em Agronegócio, Universidade Federal de Mato Grosso do Sul, Campo Grande, 2006.

RESTAURANTE POPULAR REABRE APÓS 6 MESES. Folha de Londrina, Londrina, 6 jan. 2014. p. 2.

SANTOS, R. C. Estudo investiga alimentação de idosos, Jornal da Unicamp, 2003.

Disponível em: <www.unicamp.br/unicamp/unicamphoje/ju/julho2003/ju220pg08. html>. Acesso em: 18 jun. 2014.

SANTOS, A. R. Metodologia científica: a construção do conhecimento. 6. ed. Rio de Janeiro: DP\&A, 2004.

SCHMIDT, M. I. Doenças crônicas não transmissíveis no Brasil: carga e desafios atuais.

Saúde no Brasil, Online, v. 4, p. 1-14, mai. 2011.

SEVERINO, A. J. Metodologia do Trabalho Científico. 23. ed. São Paulo: Cortez, 2007. SIEVERT, M.; TAÍSE, J. V. Nova geração de idosos: um consumidor a ser conquistado (artigo). In: X Conferência Brasileira de Comunicação e Saúde - Com Saúde, São Paulo, 2007. SILVA, S. V.; LIMA, K. C. Prevalência e fatores associados ao risco de desnutrição em idosos institucionalizados. In: Congresso Internacional de Envelhecimento Humano, 3, Campina Grande, 2013. Disponível em: <http://www.editorarealize.com.br/revistas/ cieh/trabalhos/Comunicacao_999.p>. Acesso em: 19 jun. 2014. 
TINÔCO, A. L. A. et al. Caracterização do padrão alimentar, da ingestão de energia e nutrientes da dieta de idosos de um município da Zona da Mata Mineira - Dieta de idosos. Revista Brasileira Geriatria e Gerontologia, Rio de Janeiro, v. 10, n. 3, 2007. VERGARA, S. C. Projetos e relatórios de pesquisa em administração. São Paulo: Atlas, 2005.

WOORTMANN, K. A comida, a família e a construção do gênero feminino. Revista de Ciências Sociais, Rio de Janeiro, v. 29, n. 1, 1986. 
